\title{
DOCUMENTO
}

\section{Recomendaciones para el diagnóstico microbiológico de la infección urinaria}

\author{
COMITE DE MICROBIOLOGIA CLINICA. SOCIEDAD CHILENA DE INFECTOLOGIA* \\ GUIDELINES FOR MICROBIOLOGICAL DIAGNOSIS \\ OF THE URINARY TRACT INFECTION
}

\section{INTRODUCCION}

Este documento es una recomendación para el procesamiento de los urocultivos e intenta unificar los criterios para la interpretación de este examen en los laboratorios de microbiología. La necesidad surgió a raíz de una encuesta realizada a 15 laboratorios de microbiología en hospitales chilenos, en la cual se analizaron 46.103 urocultivos ${ }^{1}$. Estas recomendaciones están fundamentadas en las Guías de la Sociedad Americana de Microbiología ${ }^{2}$ y en el aporte de los miembros de Comité de Microbiología Clínica de la Sociedad Chilena de Infectología, considerando las dificultades y problemas a los que puede verse enfrentado el microbiólogo en su práctica profesional

\section{Consideraciones generales respecto de la infección del tracto urinario}

La infección del tracto urinario (ITU) es la infección bacteriana más común en humanos, producida por un número limitado de bacterias conocidas como especies uropatógenas.
La muestra de orina para urocultivo es la más frecuentemente recibida y procesada en los laboratorios de microbiología. Aproximadamente 20 a $22 \%$ de los urocultivos tienen un resultado positivo ${ }^{1}$. La presencia de bacterias en la orina puede corresponder a varios síndromes clínicos que poseen mecanismos patogénicos propios y significado clínico, tratamiento y pronóstico diferentes, dependiendo del tipo de huésped.

\section{Síndromes clínicos}

Es necesario distinguir al menos cuatro diferentes síndromes clínicos que se describen en la Figura 1: bacteriuria asintomática, cistitis, síndrome uretral agudo y pielonefritis aguda.

\section{Obtención de muestra}

Se considera una etapa crucial en el procesamiento de los urocultivos ya que la posibilidad de contaminación con bacterias de la flora comensal de piel, periné y uretra distal, es muy

\footnotetext{
* Miembros: Stephanie Braun J., Rossanna Camponovo C., Erna Cona T., Alejandra Fernández V., Patricia García C., Patricia González A., Beatrice Hervé E., Chrystal Juliet L., María Eugenia Pinto C., Valeria Prado J., Olivia Trucco A. y Vjera Triantafilo V.
} 


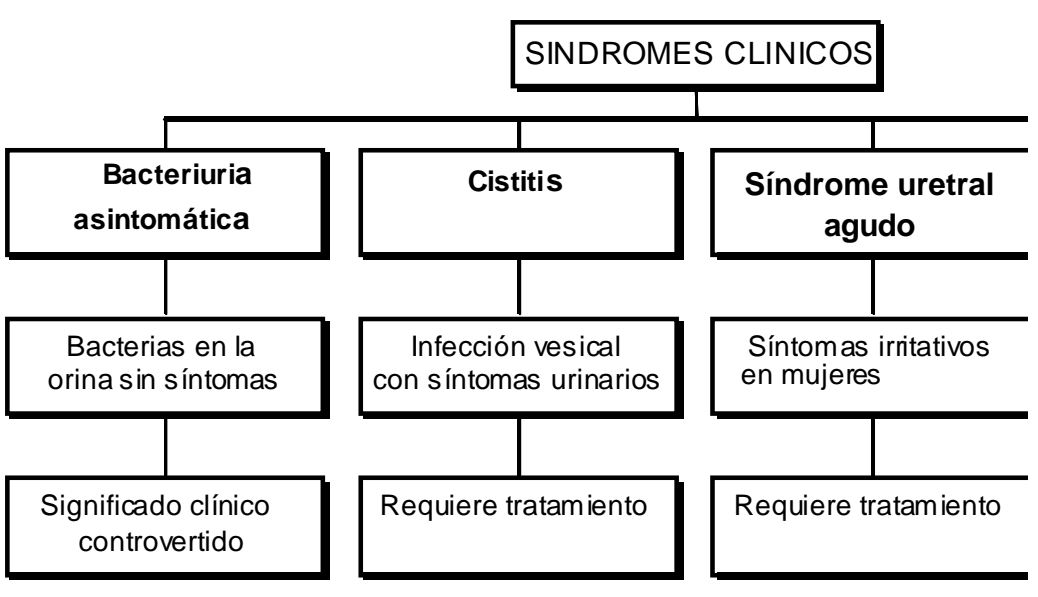

aguda

Figura 1. Síndromes clínicos asociados a infección del tracto urinario.

alta e induce a la generación de resultados falsamente positivos. La Sociedad Americana de Microbiología considera aceptable un porcentaje de contaminación en las muestras de orina no superior a $5 \%$.

Se describen al menos 5 métodos para la obtención de orina a cultivar, los que se muestran en la Figura 2.

\section{Recomendaciones}

- Preferentemente se debe obtener la primera orina de la mañana (ya que se trata de una muestra más concentrada). De no ser posi- ble, el paciente debe abstenerse de orinar durante las 3 horas previas al examen.

- No forzar la ingestión de líquidos, ya que con ello se diluye la orina, alterando el recuento.

- Volumen recomendado a recolectar: 25 a $50 \mathrm{ml}$.

- Volumen mínimo: $3 \mathrm{ml}$.

\section{Métodos para la obtención de la muestra de orina}

Orina de segundo chorro: es la muestra más frecuentemente procesada para urocultivo, en especial por su fácil obtención; sin embargo,

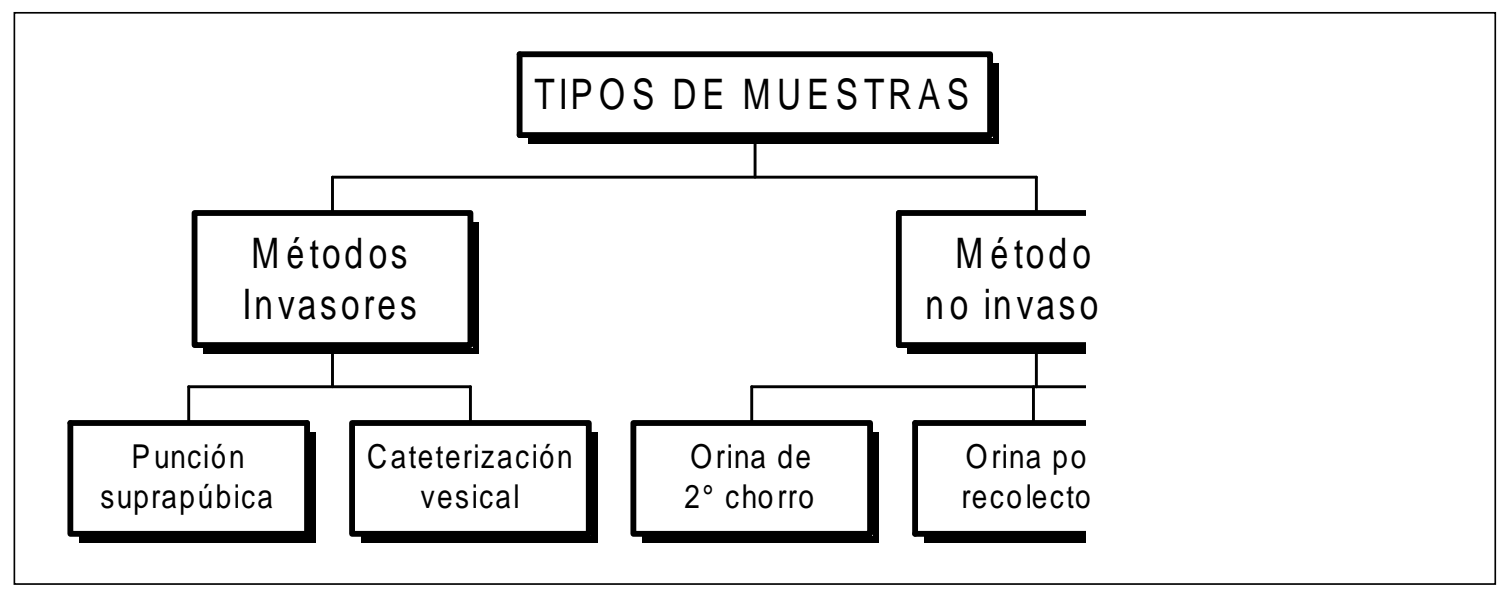

Figura 2. Métodos para la obtención y clasificación de la muestra de orina para urocultivo. 
se puede contaminar frecuentemente con flora de la piel, uretra, y vagina en mujeres. Requiere de un aseo genital prolijo con tórulas, agua y jabón.

Orina obtenida mediante recolector: no en una buena muestra, ya que generalmente se contamina con flora perineal. Es útil sólo si el cultivo resulta ser negativo o si se aisla, en recuento significativo, una especie uropatógena única. Para este procedimiento se recomienda el cambio de recolector cada 30 minutos hasta obtener la muestra de orina.

Orina obtenida a través de catéter vesical permanente: no es una buena muestra excepto que el catéter haya sido recientemente instalado. Generalmente los catéteres vesicales están colonizados ya a las 48 horas de instalados ${ }^{4}$ y los microorganismos aislados no necesariamente son el agente causal de la infección urinaria.

La superficie externa del catéter debe limpiarse con una tórula con alcohol $70 \%$ y esperar que seque. La punción se efectúa en un ángulo de $30^{\circ}$ en el sitio indicado para ello. No debe pinzarse el catéter antes de obtener la muestra.

Punción vesical: es el método de referencia para la obtención de orina a cultivar ya que evita la contaminación con flora uretral; sin embargo, se reserva para casos especiales por ser un procedimiento invasor.

Cateterización vesical transitoria: se considera una alternativa a la punción vesical pero es también un procedimiento invasor y puede generar arrastre retrógrado de microorganismos.

\section{Solicitud de examen al laboratorio}

El laboratorio debe educar a los médicos clínicos para que la solicitud de urocultivo contenga la siguiente información fundamental para el procesamiento y la interpretación de los resultados:

- nombre, edad y sexo del paciente

- si es mujer, indicar la presencia de embarazo.

- existencia de patología de la vía urinaria

- método empleado en la recolección de la muestra

- diagnóstico clínico
- uso previo de antibióticos

- hora de obtención de la muestra

\section{Transporte de la muestra}

La orina es un buen medio de cultivo que permite la multiplicación de los microorganismos incrementando el recuento bacteriano, por lo que las muestras deben procesarse antes de 2 horas de obtenidas. Si ello no es factible, las muestras deben refrigerarse a $4^{\circ} \mathrm{C}$. Una muestra puede mantenerse refrigerada, sin que se altere el recuento bacteriano, durante 24 horas. Los preservantes que inhiben la multiplicación bacteriana no han resultado mejores que la refrigeración, son de alto costo y tienen el inconveniente de interferir con algunas determinaciones de la tira reactiva de orina.

\section{Procesamiento en el laboratorio}

Existen diversos procedimientos de ayuda en el diagnóstico de la ITU (Figura 3). Clásicamente, el método de referencia es el urocultivo cuyo procesamiento demora 24 a 48 horas. Se recomienda guardar las muestras de orina refrigeradas después de ser procesadas, hasta obtener el resultado del cultivo. En caso de resultados discordantes se recurrirá a la muestra almacenada para repetir los análisis.

\section{Tests de screening rápidos}

\section{Examen microscópico del sedimento urinario}

Sugiere infección urinaria, sin embargo, no es confirmatorio. Permite aproximación correcta en $\sim 70 \%$ de las veces ${ }^{5,6}$.

La estandarización de los sedimentos urinarios y el uso de cámaras de recuento (sistema KOVA $\left.{ }^{\circledR}\right)$ han permitido uniformar variables como el volumen de la orina a centrifugar, el volumen en el que se resuspende el sedimento y el tamaño de la gota que se observa al microscopio $^{7}$; sin embargo, el alto costo dificulta su disponibilidad en la mayoría de los laboratorios. 


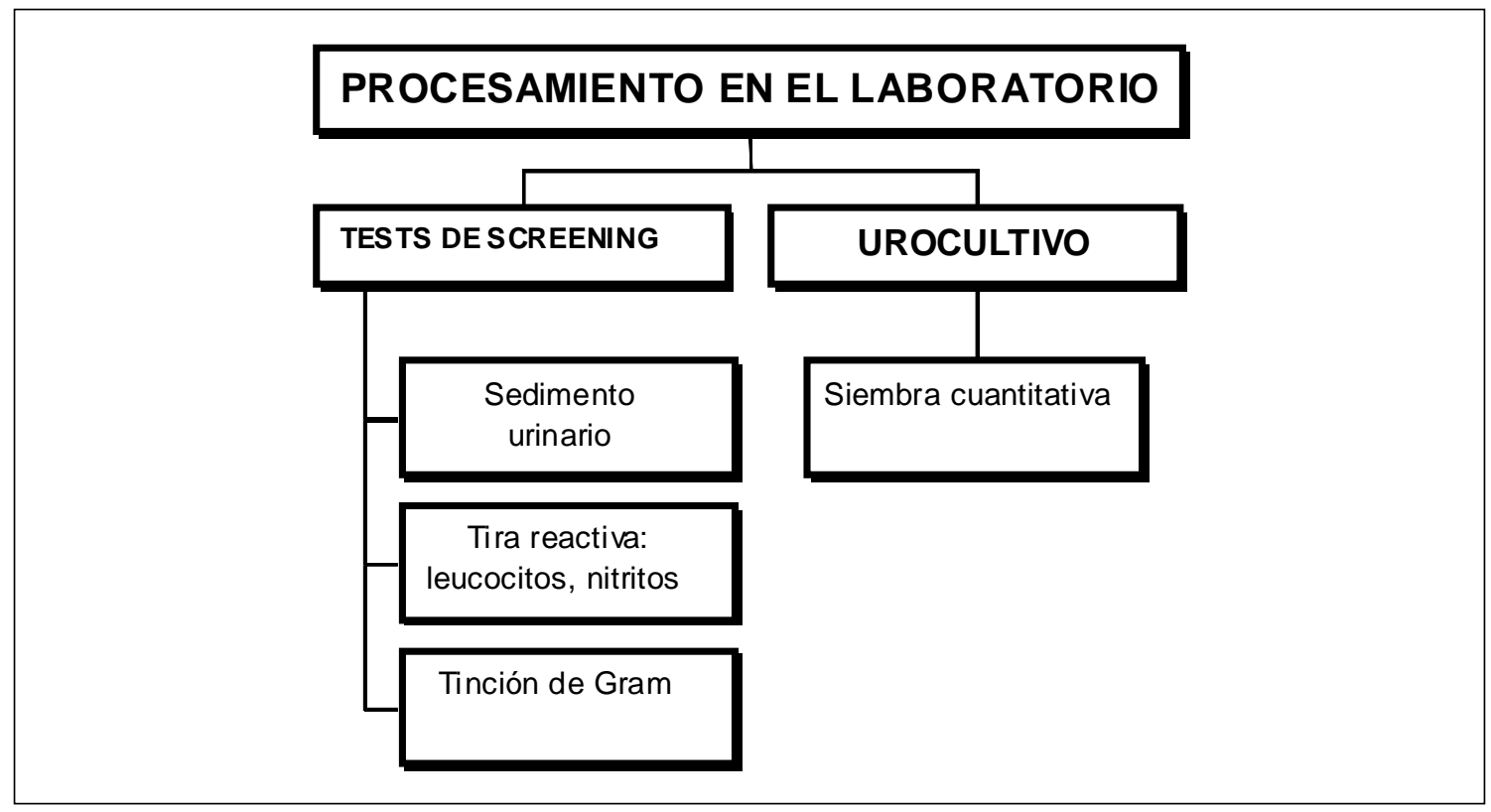

Figura 3. Procesamiento de la muestra en que se sospecha una infección urinaria.

La recomendación es uniformar las variables susceptibles de controlar como el volumen de la orina a centrifugar (que debe ser idealmente de 10 a $12 \mathrm{ml}$ ), el tiempo de centrifugación (5 minutos) y la velocidad de centrifugación $(400 \mathrm{~g})^{7,8,11}$. Para convertir la fuerza centrífuga relativa $(\mathrm{g})$ en revoluciones por minuto ( $\mathrm{rpm})$ es necesario conocer el radio del rotor de la centrífuga $(\mathrm{r})$ :

$$
(\mathrm{rpm})^{2}=10^{5} \mathrm{xg} / 1.12 \times \mathrm{r}(\mathrm{cm})
$$

Se define piuria como la presencia de más de 10 leucocitos $/ \mu 1^{9}$ o más de 6 leucocitos alterados por campo de $40 \mathrm{x}^{10,11}$. La presencia de piuria indica inflamación del tracto urogenital. Cuando existe infección, bacterias y neutrófilos se ven juntos formando placas de pus, las que son de utilidad en la orientación de infección urinaria pero inespecíficas. Se ha descrito que hasta $10 \%$ de niños con fiebre sin infección urinaria tenía leucocituria ${ }^{12}$ y que por otra parte hasta $50 \%$ de los niños con infección urinaria con cultivo positivo tenían sedimento urinario normal ${ }^{13}$.

Una limitación del análisis del sedimento urinario es ser operador dependiente.

\section{Tira reactiva de orina}

En general son dos los parámetros útiles a evaluar en la tira reactiva o examen químico de orina:

- Presencia de leucocitos mediante la detección de su enzima: leucocito esterasa. Detecta leucociturias $>10$ leucocitos $/ \mu \mathrm{l}$ con una sensibilidad entre 53 y $95 \%{ }^{15,16}$.

- Presencia de nitritos. La mayoría de las especies uropatógenas reducen nitratos a nitritos excepto Staphylococcus saprophyticus y Enterococcus sp.

Se requieren al menos 6 horas para producir niveles detectables de nitritos, por lo que debe realizarse en la primera micción matinal.

La sensibilidad descrita es de $\sim 80 \%$ en la primera micción matinal disminuyendo a $30 \%$ en otras muestras. Su especificidad es muy buena, cercana a $98 \%{ }^{17}$.

\section{Tinción de Gram directa de la muestra}

Es un método rápido, económico, sensible y específico para detectar bacteriuria. Se recomienda realizarlo como respaldo frente a discordancias o hallazgos especiales más que como screening. Debe aplicarse a la muestra recién 
agitada sin centrifugar, con el mismo asa de $1 \mu \mathrm{l}$ (o de $10 \mu \mathrm{l}$ ) empleado en la siembra del urocultivo, depositando este volumen en un portaobjetos; pueden colocarse hasta 10 muestras por lámina. Estas se tiñen y pueden ser observadas cuando existen discordancias entre el urocultivo y el sedimento.

La presencia de una bacteria/campo de inmersión tiene buena correlación con > 100.000 ufc/ml en $\sim 85 \%$ de los casos².

\section{Urocultivo}

\section{Siembra microbiológica}

La metodología de la inoculación de la muestra en medios de cultivo o siembra microbiológica depende de la forma de obtención de la muestra:

- Para orinas de segunda micción, recolector y catéter a permanencia, las muestras deben sembrarse con asa de $1 \mu \mathrm{l}$ en placas de agar sangre y algún medio selectivo-diferencial: Mac Conkey; UTI ${ }^{\mathrm{TM}}$, Oxoid; CPS ${ }^{\mathrm{TM}}$, bioMerieux ${ }^{18,19}$. El desarrollo de una colonia en el cultivo debe multiplicarse por 1.000.

- Para orinas obtenidas por cateterización vesical, las muestras pueden sembrarse con asa de $10 \mu(1$ colonia $=100 \mathrm{ufc} / \mathrm{ml})$ y $1 \mu \mathrm{l}$ ( 1 colonia $=1.000 \mathrm{ufc} / \mathrm{ml})$.

- Para orinas obtenidas por punción vesical, se recomienda la siembra por inundación en agar sangre más un medio selectivo-diferencial para bacilos Gram negativos o siembra directa de $100 \mu \mathrm{l}(1$ colonia $=10 \mathrm{ufc} / \mathrm{ml})$.

\section{Incubación}

Una vez sembradas las placas deben incubarse durante 16 a 18 horas a $35-37^{\circ} \mathrm{C}$. Incube 48 horas aquellos urocultivos negativos con sedimento urinario alterado.

\section{Informe del resultado}

Al momento de informar los urocultivos, se recomienda revisar el resultado del sedimento urinario para que ambos informes sean concordantes.

Es necesario definir qué se entiende por sedimento sugerente de ITU para poder eva- luar las discordancias entre el sedimento y el urocultivo:

Piocitos: $\quad>10 / \mathrm{ul}$ ó $>$ de $5-6$ por campo de $40 \mathrm{x}$

Leucocitos: > $10 / \mathrm{ul}$ ó > de 5-6 por campo de 40x

Bacterias: Regular o abundante cantidad

La presencia de células descamativas y/o mucus en una paciente mujer, sugiere que la muestra está contaminada con secreción vaginal.

\section{Discordancias y conductas a seguir}

Urocultivo negativo con sedimento alterado. En estos casos resulta de utilidad para aclarar la discordancia:

- Observar la tinción de Gram de la muestra directa en busca de bacterias y su asociación con células inflamatorias (leucocitos o piocitos).

- Reincubar la placa durante 48 horas.

- De ser posible, solicitar nueva muestra.

- Comunicarse con el médico tratante ya que existen otras causas de sedimento urinario alterado que no corresponden a ITU o para saber si el paciente está recibiendo antibióticos.

- Resembrar la orina con asa calibrada de $10 \mu \mathrm{l}$.

Urocultivo positivo con sedimento normal. Informar recuento y el agente identificado para que el médico tratante tome la decisión, basado en el cuadro clínico.

\section{INTERPRETACION}

Se basa fundamentalmente en el recuento de colonias, en algunos datos clínicos, en el resultado del sedimento urinario, en la forma de obtención de la muestra y en el tipo y número de microorganismos aislados, según se muestra en las Tablas 1 y 2 . Las recomendaciones de la Tabla 1 están fundamentadas en la literatura $^{2,20,21}$ y en la práctica microbiológica de los integrantes del Comité de Microbiología, por lo pueden ser necesarios algunos ajustes locales, según la realidad de cada laboratorio. 
Tabla 1. Interpretación microbiológica del urocultivo y conducta recomendada

\begin{tabular}{|c|c|c|c|c|}
\hline $\begin{array}{l}\text { Recuento de } \\
\text { colonias } \\
(\mathrm{UFC} / \mathrm{ml})\end{array}$ & $\begin{array}{l}\text { Condición clínica } \\
\text { o método de } \\
\text { recolección }\end{array}$ & Sedimento urinario & $\begin{array}{l}\text { Microorganismo(s) } \\
\text { aislado(s) }\end{array}$ & $\begin{array}{l}\text { Interpretación/ } \\
\text { Conducta } \\
\text { recomendable }\end{array}$ \\
\hline 0 & - & Independiente del resultado & - & Urocultivo negativo \\
\hline $\begin{array}{l}\text { Cualquier } \\
\text { recuento }\end{array}$ & Punción suprapúbica & Independiente del resultado & Cualquier microorganismo & $\begin{array}{l}\text { Identificación y } \\
\text { estudio de } \\
\text { susceptibilidad }\end{array}$ \\
\hline 1.000 & $\begin{array}{l}\text { Cateterización } \\
\text { transitoria }\end{array}$ & Independiente del resultado & $\begin{array}{l}\leq 2 \text { especies } \\
\text { uropatógenas }\end{array}$ & Idem \\
\hline$\geq 10.000$ & $\begin{array}{l}\text { Segunda micción en } \\
\text { paciente especial* }\end{array}$ & Independiente del resultado & $\begin{array}{l}\leq 2 \text { especies } \\
\text { uropatógenas }\end{array}$ & Idem \\
\hline$\geq 10.000$ & $\begin{array}{l}\text { Orina por catéter } \\
\text { permanente }\end{array}$ & Patológico & $\begin{array}{l}\leq 2 \text { especies } \\
\text { uropatógenas }\end{array}$ & Idem \\
\hline$\geq 10.000$ & Segunda micción & Patológico & $\begin{array}{ll}\leq 2 & \text { especies } \\
& \text { uropatógenas }\end{array}$ & Idem \\
\hline$\geq 100.000$ & Segunda micción & Patológico & $\begin{array}{l}2 \text { uropatógenos + otra } \\
\text { bacteria con recuento } \\
10 \text { veces menos }\end{array}$ & $\begin{array}{l}\text { Identificación y } \\
\text { susceptibilidad sólo } \\
\text { de los uropatógenos }\end{array}$ \\
\hline$\geq 100.000$ & Segunda micción & $\begin{array}{l}\text { Sin antecedente del } \\
\text { sedimento }\end{array}$ & $\begin{array}{ll}\leq 2 & \text { especies } \\
& \text { uropatógenas }\end{array}$ & $\begin{array}{l}\text { Identificación y } \\
\text { estudio de } \\
\text { susceptibilidad }\end{array}$ \\
\hline$\geq 100.000$ & - & - & 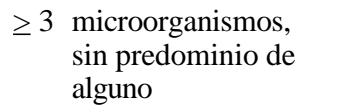 & $\begin{array}{l}\text { Polimicrobismo. } \\
\text { Solicite nueva muestra }\end{array}$ \\
\hline
\end{tabular}

*Mujer embarazada, paciente diabético o urológico

Tabla 2. Microorganismos más frecuentemente aislados en urocultivos

\begin{tabular}{|c|c|c|c|c|c|}
\hline $\begin{array}{c}\text { Especies } \\
\text { uropatógenas } \\
\text { comunes: } \\
\text { (Crecen en } 24 \text { horas) }\end{array}$ & $\begin{array}{l}\text { Especies que pueden } \\
\text { ser uropatógenas: } \\
\text { (Requieren incubación } \\
\text { prolongada o siembra }\end{array}$ & $\begin{array}{c}\text { Especies no } \\
\text { uropatógenas } \\
\text { (Flora residente) }\end{array}$ & $\begin{array}{l}\text { Especies uropatógenas } \\
\text { poco comunes } \\
\text { (No crecen en medios } \\
\text { de rutina) }\end{array}$ & $\begin{array}{l}\text { Especies uropatógenas } \\
\text { relacionadas a } \\
\text { catéteres vesicales de } \\
\text { corta duración }\end{array}$ & $\begin{array}{l}\text { Especies uropatógenas } \\
\text { relacionadas a } \\
\text { catéteres vesicales } \\
\text { de larga duración }\end{array}$ \\
\hline $\begin{array}{l}\text { Escherichia coli } \\
\text { Klebsiella spp } \\
\text { Proteus spp } \\
\text { Pseudomonas } \\
\text { aeruginosa } \\
\text { Enterobacter spp } \\
\text { Enterococcus spp } \\
\text { Staphylococcus } \\
\text { saprophyticus } \\
\text { Staphylococcus } \\
\text { aureus } \\
\text { Morganella morganii } \\
\text { Streptoccoccus } \\
\text { agalactiae } \\
\text { Candida spp (puede } \\
\text { ser contaminante) }\end{array}$ & $\begin{array}{l}\text { Gardnerella vaginalis } \\
\text { Haemophilus influenzae } \\
\text { Haemophilus } \\
\text { parainfluenzae } \\
\text { Corynebacterium } \\
\text { urealyticum }\end{array}$ & $\begin{array}{l}\text { Lactobacillus } \\
\text { Difteroides } \\
\text { (Corynebacterium) } \\
\text { Streptococcus grupo } \\
\text { viridans } \\
\text { Micrococcus } \\
\text { Staphylococcus } \\
\text { coagulasa negativa } \\
\text { diferentes de } S \text {. } \\
\text { saprophyticus y } S \text {. } \\
\text { epidermidis } \\
\text { Actinomyces spp } \\
\text { Bacillus spp }\end{array}$ & $\begin{array}{l}\text { Neisseria } \\
\text { gonorrhoeae } \\
\text { Chlamydia } \\
\text { trachomatis } \\
\text { Ureaplasma } \\
\text { urealyticum } \\
\text { Mycobacterium } \\
\text { tuberculosis }\end{array}$ & $\begin{array}{l}\text { Escherichia coli } \\
\text { Providencia } \\
\text { stuartii } \\
\text { Klebsiella } \\
\text { pneumoniae } \\
\text { Proteus mirabilis } \\
\text { Pseudomonas } \\
\text { aeruginosa } \\
\text { Staphylococcus } \\
\text { coagulasa negativa } \\
\text { (S. epidermidis) } \\
\text { Enterococcus spp } \\
\text { Candida } \text { spp }\end{array}$ & $\begin{array}{l}\text { Providencia stuartii } \\
\text { Morganella morganii } \\
\text { Proteus mirabilis } \\
\text { Escherichia coli } \\
\text { Pseudomonas } \\
\text { aeruginosa } \\
\text { Klebsiella } \\
\text { pneumoniae } \\
\text { Staphylococcus } \\
\text { coagulasa negativa } \\
\text { Enterococcus spp } \\
\text { Candida spp }\end{array}$ \\
\hline
\end{tabular}




\section{BIBLIOGRAFIA}

1.- Comité de Microbiología Clínica. Encuesta sobre métodos de diagnóstico microbiológico de la infección urinaria. Rev Chil Infect 2001; 18 (1): 34-8.

2.- CLARRIDGE J E, JOHNSON J R, PEZZLO M T. Laboratory Diagnosis of Urinary Tract Infections. CUMITECH (Cumulative Techniques and Procedures in Clinical Microbiology) ASM Press 2B. Nov 1998, pp 1-19.

3.- VALENSTEIN P, MEIER F. Urine culture contamination: A College of American Pathologists Q-Probes study of contaminated urine cultures in 906 institutions. Arch Pathol Lab Med 1998; 122: 123-9.

4.- MARRIE T J, COSTERTON J W. A scanning electron microscopic study of urine droppers and urine collecting systems. Arch Intern Med 1983; 143: 1135-

5.- CORMAN L I, FOSHEE W S, KOTCHMAR G S, HARBISON R W. Simplified urinary microscopy to detect significant bacteriuria. Pediatrics 1982; 70: 133-5.

6.- GINSBURG C M, MCCRACKEN G H. Urinary tract infections in young infants. Pediatrics 1982; 69: 409.

7.- HABER M H. Standardized urine analysis. Clin Lab Med. 1988; 8: 437-47.

8.- KING S. urine analysis and body fluids. Second Edition. FA Davis Company. Philadelphia. 1989, pp 87-115

9.- SOBEL J D, KAYE D. Urinary tract infections. In: Mandell, Douglas \& Bennett's Principles and Practice of Infectious Diseases. Mandell G L, Bennett J E, Dolin R, eds. 5th edition, 2000. Churchill Livingstone, New York, pp: 773-805.

10.- JOHN BERNARD HENRY M D. Clinical Diagnosis and Management by Laboratory Methods .18 th edition,1991, Saunders, Philadelphia, pp 387-444.

11.- Procedimientos Técnicos de Laboratorio Clínico. Ins- tituto de Salud Pública de Chile. 1994. Volumen III.pp 86-8.

12.- TURNER G M, COULTHARD M G. Fever can cause pyuria in children. Br Med J 1975; 311: 924.

13.- CRAIN E F, GERSHEL J C. Urinary tract infections in febrile infants younger than 8 weeks of age. Pediatrics. 1990; 86: 363-7.

14.- LACHS M S, NACHAMKIN Y, EDELSTEIN P, GOLDMAN J, FEINSTEIN A R, SCHWARTZ J S. Spectrum bias in the evaluation of diagnostic tests: Lessons from the rapid test for urinary tract infection. Ann Intern Med 1992; 117: 135-40.

15.- HOLLAND D J, BLISS K J, ALLEN C D, GILBERT G L. A comparison of chemical dipsticks read visually or by photometry in the routine screening of urine specimens in the clinical microbiology laboratory. Pathol 1995; 27: 91-6.

16.- KUSUMI R K, GROVER P G, KUNIN C M. Rapid detection of pyuria by leukocyte esterase activity. JAMA. 1981; 245: 1653.

17.- SODEMAN T M. Contemporary Issues in Clinical Microbiology. A practical strategy for diagnosis of urinary tract infections. Sodeman, Clinics in Laboratory Medicine. 1995; 15: 235-50.

18.- REISNER B S, AUSTIN E F. Evaluation of CPS ID2 chromogenic agar as a single medium for urine culture. Diagn Microbiol Infect Dis 1997; 28: 113-7.

19.- HENGSTLER K A, HAMMANN R, FAHR A M. Evaluation of BBL CHROMagar orientation medium for detection and presumptive identification of urinary tract pathogens. J Clin Microbiol 1997; 35: 2773-7.

20.- Urine Culture Procedure. In: HD. Isenberg. Eds, Clinical Microbiology Procedures Handbook. 1992, ASM Press, Washington, DC, 1.17.1-1.17.15

21.- REISNER B S, WOODS G L, THOMPSON RB, LARONE D H, GARCÍA L S, SHIMIZU R Y. Specimen Processing. In: Murray P R, Baron E J, Pfaller M A, Tenover F C, Yolken R H. Eds, Manual of Clinical Microbiology. 7th ed,1999, ASM Press, Washington, pp 64-104.

Correspondencia a:

Patricia García Cañete

Laboratorio de Microbiología

Universidad Católica de Chile

Av. Vicuña Mackenna 4686

Macul, Santiago, Chile

E-mail:pgarcia@med.puc.cl 